\title{
Chromosomal Microarray Analysis in Pregnancies With Corpus Callosum or Posterior Fossa Anomalies
}

Lior Greenbaum, MD, PhD, Idit Maya, MD, Lena Sagi-Dain, MD, Rivka Sukenik-Halevy, MD, Michal Berkenstadt, PhD, Hagith Yonath, MD, Shlomit Rienstein, PhD, Adel Shalata, MD, PhD, Eldad Katorza, MD, MSc, MBA, and Amihood Singer, MD

Neurol Genet 2021;7:e585. doi:10.1212/NXG.0000000000000585
Correspondence

Dr. Greenbaum

lior.greenbaum@sheba.health.gov.il

\section{Abstract}

\section{Objective}

We investigated the detection rate of clinically significant chromosomal microarray analysis (CMA) results in pregnancies with sonographic diagnosis of fetal corpus callosum anomalies (CCA) or posterior fossa anomalies (PFA).

\section{Methods}

All CMA tests in pregnancies with CCA or PFA performed between January 2015 and June 2020 were retrospectively evaluated from the Israeli Ministry of Health database. The rate of CMA with clinically significant (pathogenic or likely pathogenic) findings was calculated and compared to a local Israeli cohort of 5,541 pregnancies with normal ultrasound.

\section{Results}

One hundred eighty-two pregnancies were enrolled: 102 cases with CCA and 89 with PFA (9 cases had both). Clinically significant CMA results were found in 7/102 of CCA (6.9\%) and in $7 / 89$ of PFA $(7.9 \%)$ cases. The CMA detection rate in pregnancies with isolated CCA $(2 / 57$, $3.5 \%)$ or PFA $(2 / 50,4.0 \%)$ was lower than in nonisolated cases, including additional CNS and/or extra-CNS sonographic anomalies (CCA-5/45, 11.1\%; PFA-5/39, 12.8\%), but this was not statistically significant. However, the rate among pregnancies that had extra-CNS anomalies, with or without additional CNS involvement (CCA-5/24, 20.8\%; PFA-5/29, 17.2\%), was significantly higher compared to all other cases ( $p=0.0075$ for CCA; $p=0.035$ for PFA). Risk of CMA with clinically significant results for all and nonisolated CCA or PFA pregnancies was higher compared to the background risk reported in the control cohort $(p<0.001)$, but was not significant for isolated cases.

\section{Conclusions}

Our findings suggest that CMA testing is beneficial for the genetic workup of pregnancies with CCA or PFA, and is probably most informative when additional extra-CNS anomalies are observed. 


\section{Glossary}

$\mathbf{C C}=$ corpus callosum; $\mathbf{C C A}=$ corpus callosum anomalies; $\mathbf{C I}=$ confidence interval; $\mathbf{C M A}=$ chromosomal microarray analysis; CNV = copy number variant; $\mathbf{L C R}=$ low copy repeat; $\mathbf{M O H}=$ Ministry of Health; NIPS = noninvasive prenatal screening; PFA = posterior fossa anomalies; US = ultrasound; VUS = variant of unknown significance.

Chromosomal microarray analysis (CMA), aimed at detecting microscopic and submicroscopic chromosomal aberrations, is an important tool for the genetic analysis of fetuses with abnormal sonographic findings. ${ }^{1-3}$ CMA is considered a primary test for women undergoing invasive prenatal diagnosis due to one or more fetal structural anomalies. ${ }^{4,5}$ In the presence of a normal karyotype, CMA can detect clinically relevant deletions or duplications in $6 \%$ of pregnancies with structural anomaly in ultrasound (US). ${ }^{3}$

Fetal CNS anomalies detected by prenatal US are an important referral indication for genetic counseling. In the current study, we focused on 2 groups of CNS anomalies: corpus callosum anomalies (CCA) and posterior fossa anomalies (PFA). In addition to various environmental factors, genetic causes such as copy number variants (CNVs) or point mutations in multiple genes have been reported to play a role in the etiology of these anomalies. ${ }^{6-10}$

The corpus callosum (CC) is the largest white matter tract in the human brain, connecting the 2 cerebral hemispheres. ${ }^{11}$ Generally, CCA include complete or partial agenesis, hypoplasia, thickening, irregular shape, and other findings. ${ }^{8-10,12}$ Each may be isolated or combined with additional CNS and extra-CNS findings, leading to a wide range of clinical manifestations. ${ }^{8,13,14}$ A population-based study in California found that the combined prevalence of CC agenesis and hypoplasia was 1.8 per 10,000 live births. ${ }^{15}$ However, in developmentally disabled individuals, the prevalence of CC agenesis, determined by $\mathrm{CT}$, reaches to $2.3 \%{ }^{16}$

PFA encompasses a heterogeneous group of morphologically defined cystic and noncystic conditions. ${ }^{6,717-19}$ Among them are cerebellar hypoplasia, vermian hypoplasia or agenesis, Dandy-Walker malformation, Blake pouch cyst, arachnoid cyst, and mega cisterna magna. ${ }^{7,17,19}$ The prevalence, involved pathophysiology, and future outcomes are variable, depending on the specific anomaly type. ${ }^{20,21}$ For example, the estimated birth prevalence of cerebellar hypoplasia was 1.3 per 100,000 persons. ${ }^{22}$ For Dandy-Walker Malformation, the overall and live birth prevalence were 6.79 and 2.74 per 100,000 births, respectively. ${ }^{23}$

There are relatively limited data regarding the yield of CMA in prenatal diagnosis of $\mathrm{CCA}^{24-28}$ and PFA, ${ }^{26,28-32}$ which vary between studies and are influenced by several factors, such as the specific anomaly type and involvement of additional CNS or extra-CNS anomalies.
The Israeli Ministry of Health $(\mathrm{MOH})$ cohort of CMA performed due to fetal sonographic anomalies was previously described and used to evaluate the risk of clinically significant CMA results in various types of anomalies. ${ }^{33-46}$ In this study, we investigated the frequency of CMA with clinically significant findings in pregnancies with CCA or PFA and compared it to pregnancies with normal US.

\section{Methods}

\section{Data Acquisition}

A retrospective search was conducted in a computerized database of all CMA tests reported to the Israeli MOH between January 2015 and June 2020 (inclusive). Generally, every pregnant woman in Israel is recommended to undergo 2 routine sonographic anatomic surveys for the fetus (at 14-16 and at 20-23 weeks of gestation). If abnormal US findings are observed, the woman is referred to genetic counseling. For major anomalies (including CCA and PFA), invasive prenatal testing (usually amniocentesis) for CMA is advised, which is reimbursed by the $\mathrm{MOH}$. Testing reports are transferred to the department of community genetics at the MOH. Data are recoded in an electronic database, including information about the indication for testing, summary of genetic counseling, and CMA results.

In the present study, we enrolled only CMA performed for pregnancies with fetal diagnosis of CCA or PFA detected by prenatal US (few cases had both CCA and PFA). CCA included hypoplastic (thin) CC, short or short and thick CC, complete or partial agenesis of the CC, large or hyperplastic CC, and other or unspecified CCA. PFA included cerebellar and vermian anomalies (such as agenesis, hypoplasia, and dysplasia), DandyWalker malformation, Blake pouch cyst, mega cisterna magna, arachnoid cyst, and other or unspecified PFA.

All cases were retrieved and classified as isolated or nonisolated. The nonisolated cases were accompanied by other CNS and/or extra-CNS sonographic anomalies (including structural abnormalities, increased nuchal translucency, intrauterine growth restriction, oligohydramnios, and polyhydramnios). We also divided cases according to the involvement of additional extra-CNS anomalies (with or without other CNS anomalies), to compare this group to all other cases (isolated or with additional CNS anomalies only).

In fetuses with CCA, coexisting brain midline findings (e.g., in the cavum spectrum pellucidum) and colpocephaly were not classified as an additional anomaly because they probably 
constitute a part of CCA and not a separate brain anomaly. $^{24,47}$ The presence of soft markers alone (e.g., choroid plexus cyst, echogenic cardiac focus, short femur, single umbilical artery, or mild dilatation of the renal pelvis) was not considered as additional CNS or extra-CNS anomalies. We excluded pregnancies in which indications for CMA testing were missing or unclear.

\section{CMA Procedure and Interpretation of Results}

As the $\mathrm{MOH}$ database encompasses reports from several laboratories in Israel, various platforms were used to perform the CMA, as described elsewhere. ${ }^{34,37,39,41}$ Briefly, most laboratories used CytoScan $750 \mathrm{~K}$ array (Affymetrix, Santa Clara, CA), whereas others used Infinium OmniExpress-24 v 1.2 BeadChip (Illumina Inc, San Diego, CA), GenetiSure Unrestricted CGH + SNP $(4 \times 180 \mathrm{~K}) \mathrm{P} / \mathrm{N}$ G5976A Agilent (Agilent Technologies, Santa Clara, CA), or other platforms.

Several public databases were routinely applied to characterize CNVs gains or losses, among them UCSC Genome Browser (genome.ucsc.edu/), ClinVar (ncbi.nlm.nih.gov/clinvar/), Database of Genomic Variants (dgv.tcag.ca/dgv/app/home), DECIPHER (decipher.sanger.ac.uk/), ISCA Consortium (iscaconsortium.org/), and ClinGen resource (clinicalgenome. $\operatorname{org} /)$.

Following the American College of Medical Genetics and Genomics standards and guidelines for the interpretation and reporting of constitutional $\mathrm{CNVs},{ }^{48} \mathrm{CMA}$ findings were classified as pathogenic, likely pathogenic, variants of unknown significance (VUSs), likely benign and benign. Categorization was based on the original laboratory reports, which were reviewed according to updated knowledge in medical literature and the author's experience. Of note, based on the guidelines of the Israeli Medical Genetic Association in the prenatal setting, VUS deletions sized less than $1 \mathrm{Mb}$ and duplications sized less than $2 \mathrm{Mb}$ are considered below the obligatory report threshold.

We defined pathogenic and likely pathogenic findings (including both gross chromosomal aberrations and submicroscopic CNVs) as clinically significant. We excluded benign and likely benign CNVs, among them CNVs with high frequency and low penetrance, not expected to be relevant for the sonographic phenotype.

Karyotype-detectable alterations were defined as at least 10 $\mathrm{Mb}$ in size. Noninvasive prenatal screening (NIPS)-detectable CNVs refer to trisomies 13, 18, 21, XXX, XXY, XYY, and monosomy X. ${ }^{49}$

\section{Comparison to Control Cohort}

The overall frequency of clinically significant CMA results in pregnancies with CCA or PFA was compared to a cohort of 5,541 pregnancies with normal US from a single, large medical center in Israel. ${ }^{49}$ In this cohort, 78 clinically significant CMA results (1.4\%) were found. ${ }^{49}$ A similar analysis was conducted on previous studies based on the Israeli MOH CMA database, ${ }^{33-46}$ aimed to assess the risk of clinically significant CMA results in various US anomalies, compared to background risk.

We further performed an additional analysis using a subgroup of 2,752 low-risk pregnancies from this cohort (women younger than 35 years with normal serum screening, for which CMA was performed with no medical indication), with 21 clinically significant CMA findings $(0.76 \%) .{ }^{49}$

\section{Statistical Analysis}

Continuous data are described with mean and SD. Categorical data are presented as numbers and proportions. To analyze differences in CMA detection rate between groups (isolated vs nonisolated cases, and according to involvement of extraCNS anomalies), we employed the Fisher exact test, using IBM SPSS Statistics version 25 (IBM Corp, Armonk, NY).

In comparing results to pregnancies with normal US, effect estimates were calculated as relative risk with $95 \%$ confidence interval (CI). All statistical tests were 2 sided, and a $p$ value $<0.05$ was considered statistically significant.

\section{Standard Protocol Approvals, Registrations, and Patient Consents}

The study was approved by the Israeli MOH Review Board Committee (Helsinki committee) for Human Subjects. Informed consent was not required due to the retrospective data acquisition.

\section{Data Availability}

The data set analyzed during the current study is available from the corresponding author on reasonable request.

\section{Results}

From January 2015 to June 2020 (inclusive), a total of 13,266 CMA tests were reported to the MOH due to abnormal US findings during pregnancy (excluding soft signs markers). Overall, 182 cases were included in the final analysis: 102 pregnancies with CCA and 89 with PFA ( 9 cases had both CCA and PFA). CMAs with clinically significant (pathogenic or likely pathogenic) results were found in 7/102 of CCA cases $(6.9 \%)$ and similarly in $7 / 89$ of PFA cases $(7.9 \%)$ (tables 1 and 2). Information about these CMA findings and the main sonographic characteristics is presented in table 3. None of the genomic alterations recurred. Of interest, clinically significant findings were found in $2 / 9(22.2 \%)$ of the cases with both CCA and PFA. The CMA detection rates by specific type of CCA and PFA are presented in tables 1 and 2.

\section{CCA}

Among 102 pregnancies with CCA, 57 cases were isolated (55.9\%), and 45 (44.1\%) had additional sonographic anomalies (nonisolated). As presented in table 1, 21 of the nonisolated cases had additional CNS anomalies only (20.6\% of all cases), and 24 had extra-CNS anomalies (23.5\%), with or 
Table 1 Frequency of Clinically Significant CMA Results and VUSs in Pregnancies With CCA, According to the Cooccurrence of Additional Sonographic Anomalies and CCA Type

\begin{tabular}{|c|c|c|c|}
\hline & Cases $(\mathbf{N}, \%)$ & $\begin{array}{l}\text { Cases with clinically } \\
\text { significant CMA } \\
\text { results }(N, \%)\end{array}$ & $\begin{array}{l}\text { Cases with VUS } \\
(\mathrm{N}, \%)\end{array}$ \\
\hline All & 102 & $7(6.9)$ & $1(1.0)$ \\
\hline Isolated CCA & $57(55.9)$ & $2(3.5)$ & $1(1.8)$ \\
\hline Nonisolated CCA & $45(44.1)$ & $5(11.1)$ & 0 \\
\hline \multicolumn{4}{|c|}{ Nonisolated cases (CCA with additional CNS and/or extra-CNS sonographic anomalies) } \\
\hline CNS only ${ }^{a}$ & $21(20.6)$ & 0 & 0 \\
\hline Extra-CNS & $24(23.5)$ & $5(20.8)$ & 0 \\
\hline Without additional CNS anomalies & $15(14.7)$ & $3(20.0)$ & 0 \\
\hline With additional CNS anomalies ${ }^{\mathbf{b}}$ & $9(8.8)$ & $2(22.2)$ & 0 \\
\hline \multicolumn{4}{|l|}{ CCA type } \\
\hline Hypoplastic/short/short and thick CC & $42(41.2)$ & $4(9.5)$ & 0 \\
\hline Agenesis of the CC (partial or complete) & $45(44.1)$ & $3(6.7)$ & $1(2.2)$ \\
\hline Other or unspecified CCA ${ }^{c}$ & $15(14.7)$ & 0 & 0 \\
\hline \multicolumn{4}{|c|}{$\begin{array}{l}\text { Abbreviations: CC = corpus callosum; CCA = corpus callosum anomalies; CMA = chromosomal microarray analysis; PFA = posterior fossa anomalies; VUS = } \\
\text { variant of unknown significance. } \\
\text { Additional CNS sonographic anomalies: ventriculomegaly, hydrocephalus, PFA, periventricular nodular heterotopia, lissencephaly, cortical dysplasia, and } \\
\text { polymicrogyria. } \\
\text { Extra-CNS sonographic anomalies: cardiovascular (ventricular septal defect, atrioventricular canal, and coarctation of the aorta), genitourinary (echogenic } \\
\text { kidney, hydronephrosis, hypospadias, and double collecting renal system), gastrointestinal (echogenic bowel and absent or small stomach), skeletal } \\
\text { (shortening of long bones, clubfoot, polydactyly, and rib anomalies), and others (intrauterine growth restriction, oligohydramnios, micrognathia, frontal } \\
\text { bossing, and choanal atresia). } \\
\text { a Twelve cases with ventriculomegaly or hydrocephalus, } 4 \text { with PFA. } \\
\text { b Five cases with ventriculomegaly or hydrocephalus, } 5 \text { with PFA. } \\
\text { ' Seven cases with large or hyperplastic CC. }\end{array}$} \\
\hline
\end{tabular}

without additional CNS involvement. Mean maternal age was $30.4(\mathrm{SD} \pm 4.6)$ years, and mean gestational age at amniocentesis was $27.4(\mathrm{SD} \pm 5.3)$ weeks.

CMA detected 7 cases with clinically significant results in the whole group $(7 / 102,6.9 \%)$ and a total of 9 pathogenic or likely pathogenic genomic alterations (in 2 cases, 2 findings were observed in each). Of them, only $4 / 9$ (44.4\%) could have been detected by standard karyotype, and none by NIPS. VUS was observed in a single case.

A higher rate of pregnancies with clinically significant CMA results was observed in nonisolated CCA cases $(5 / 45,11.1 \%)$ compared to the isolated CCA group (2/57,3.5\%), but this was not statistically significant $(p=0.236)$. There was no significant difference in CMA detection rate between cases with isolated CCA and cases with CCA and additional CNS anomalies only $(0 / 21,0 \%)(p=1.0)$. However, the detection rate was significantly higher in pregnancies that had extra-CNS anomalies (with or without additional CNS involvement [5/24, 20.8\%]) than in isolated cases $(p=0.022)$. This effect was even more robust $(p=0.0075)$ when the detection rate in the $24 \mathrm{CCA}$ pregnancies that had extra-CNS anomalies was compared to all pregnancies without extra-CNS involvement (CCA with or without additional CNS anomalies; $2 / 78,2.6 \%)$.

\section{PFA}

Among 89 pregnancies with PFA, 50 cases were isolated $(56.2 \%)$, and $39(43.8 \%)$ had additional sonographic anomalies (nonisolated). Of these, 10 cases had additional CNS anomalies only (11.2\%), and 29 had extra-CNS anomalies (32.6\%), with or without additional CNS involvement (table 2). Mean maternal age was 29.8 ( $\mathrm{SD} \pm 5.6$ ) years, and mean gestational age at amniocentesis was $24.7(\mathrm{SD} \pm 6.3)$ weeks.

As shown in table 2, CMAs with clinically significant results were found in 7 pregnancies in the whole group (7.9\%). Nine pathogenic or likely pathogenic genomic alterations were noticed (in 2 cases, 2 findings were reported). Three of them were karyotype detectable (33.3\%), and only 1 (case 10$)$ was NIPS detectable (11.1\%). VUSs were found in 2 cases $(2 / 89,2.3 \%), 1$ in addition to other pathogenic finding in the same fetus.

The rate of CMA with clinically significant results in pregnancies with nonisolated PFA $(5 / 39,12.8 \%)$ was higher than in pregnancies with isolated PFA (2/50, 4.0\%), but was not statistically significant $(p=0.233)$. Comparing the CMA detection rate among isolated PFA to 2 subgroups of pregnancies with nonisolated PFA (additional CNS anomalies only [0/10, $0 \%]$ and extra-CNS anomalies with or without additional CNS involvement $[5 / 29,17.2 \%])$, the difference was not significant 
Table 2 Frequency of Clinically Significant CMA Results and VUSs in Pregnancies With PFA, According to the Cooccurrence of Additional Sonographic Anomalies and PFA Type

\begin{tabular}{|c|c|c|c|}
\hline & Cases (N, \%) & $\begin{array}{l}\text { Cases with clinically } \\
\text { significant CMA } \\
\text { results }(N, \%)\end{array}$ & $\begin{array}{l}\text { Cases with } \\
\text { VUS }(N, \%)^{a}\end{array}$ \\
\hline All & 89 & $7(7.9)$ & $2(2.2)$ \\
\hline Isolated PFA & $50(56.2)$ & $2(4.0)$ & 0 \\
\hline Nonisolated PFA & $39(43.8)$ & $5(12.8)$ & $2(5.1)$ \\
\hline \multicolumn{4}{|c|}{ Nonisolated cases (PFA with additional CNS and/or extra-CNS sonographic anomalies) } \\
\hline CNS only & $10(11.2)$ & $0(0)$ & $1(10)$ \\
\hline Extra-CNS & $29(32.6)$ & $5(17.2)$ & $1(3.4)$ \\
\hline Without additional CNS anomalies & $20(22.5)$ & $2(10.0)$ & 0 \\
\hline With additional CNS anomalies ${ }^{c}$ & $9(10.1)$ & $3(33.3)$ & $1(11.1)$ \\
\hline \multicolumn{4}{|l|}{ PFA type } \\
\hline Cerebellar or vermian anomalies (agenesis/hypoplasia/dysplasia) & $31(34.8)$ & $5(16.1)$ & $1(3.2)$ \\
\hline Dandy-Walker malformation & $8(9.0)$ & $1(12.5)$ & 0 \\
\hline Cystic PFA (mega cisterna magna/arachnoid cyst/Blake pouch cyst) & $40(44.9)$ & $1(2.5)$ & $1(2.5)$ \\
\hline Other or unspecified PFA & $10(11.2)$ & 0 & 0 \\
\hline
\end{tabular}

Abbreviations: CCA = corpus callosum anomalies; CMA = chromosomal microarray analysis; PFA = posterior fossa anomalies; VUS = variant of unknown significance.

Additional CNS sonographic anomalies: ventriculomegaly, hydrocephalus, CCA, cortical dysplasia, and polymicrogyria.

Extra-CNS sonographic anomalies: cardiovascular (ventricular septal defect, tetralogy of Fallot, persistent left superior vena cava, and right ventricular hypertrophy), genitourinary (echogenic kidney, polycystic kidney, and hypospadias), gastrointestinal (absent or small stomach), skeletal (shortening of long bones and clubfoot), and others (omphalocele, diaphragmatic hernia, intrauterine growth restriction, thickened nuchal fold, polyhydramnios, micrognathia, frontal bossing, choanal atresia, and soft palate malformation).

a Single case had both pathogenic finding and VUS.

${ }^{\mathrm{b}}$ Five cases with ventriculomegaly or hydrocephalus, 4 with CCA.

' Four cases with ventriculomegaly or hydrocephalus, 5 with CCA.

( $p=1.0$ and $p=0.093$, respectively). However, the detection rate in the latter group of $29 \mathrm{PFA}$ pregnancies that had extraCNS anomalies was significantly higher compared to all pregnancies without extra-CNS anomalies (PFA with or without additional CNS involvement; $2 / 60,3.3 \%)(p=0.035)$.

\section{Comparison of CMA Detection Rate to Pregnancies With Normal US (Relative Risk)}

Among all and nonisolated CCA or PFA cases, the risk for CMA with clinically significant findings was higher than for pregnancies with normal US in the whole control cohort and in a subgroup of low-risk pregnancies $(p<0.001)$ (table 4$)$. Similar results were noticed for CCA or PFA cases with extra-CNS anomalies.

The risks in isolated CCA or PFA cases, as well as of those without extra-CNS anomalies, were higher than in the whole control cohort (table 4), but were not statistically significant. However, compared with the low-risk pregnancy subgroup, the relative risks were significant $(p<0.05)$, except for CCA without extra-CNS anomalies.

As seen in table 4, the $95 \%$ CIs around the relative risk are wide. This is probably due to the small sizes of the CCA and PFA groups (compared to the much larger control cohort).
Therefore, these results and the estimated sizes of the relative risk should be interpreted with caution.

\section{Diagnostic Landscape}

As presented in table 3, interpretation of CMA results in many cases was rather straightforward. This refers to pregnancies with chromosomal aberrations such as $9 \mathrm{p}$ arm duplication (case 2), part of isochromosome 18 (6), Pallister-Killian syndrome (9), Down syndrome (10), or large microscopic CNVs containing multiple disease-causing genes. Case 14 may represent an unbalanced translocation, due to deletion of the terminal part of chromosome 1 and duplication of the terminal part of chromosome 16 (data regarding karyotype results were unavailable). The findings in part of these cases were karyotype detectable, but NIPS detectable only in case 10 .

Several other findings are of particular interest, with a probably robust genotype-phenotype correlation. A deletion of approximately $600 \mathrm{~kb}$ in $2 \mathrm{q} 22.3$, encompassing the ZEB2 gene, was found in case 5 . Heterozygous mutation in this gene causes Mowat-Wilson syndrome (MIM \#235730), in which CCA and hypospadias are described. ${ }^{50, \mathrm{e} 1}$ In case 8 of a female fetus with cerebellar hypoplasia, CMA discovered a deletion in Xp11.4 that included CASK, a gene associated with 
Table 3 Clinically Significant CMA Findings and Variants of Unknown Significance in Pregnancies With CCA and/or PFA

\begin{tabular}{|c|c|c|c|c|c|c|c|c|c|}
\hline Case & $\begin{array}{l}\text { Sonographic } \\
\text { anomalies }\end{array}$ & CMA result $($ ISCN*) array GRCh37/hg19 & $\begin{array}{l}\text { Size } \\
(\mathbf{k b})\end{array}$ & $\begin{array}{l}\text { Number } \\
\text { of OMIM } \\
\text { genes } \\
\text { (morbid } \\
\text { genes) }\end{array}$ & CNV type & CNV information & Classification & $\begin{array}{l}\text { Karyotype } \\
\text { detectable }\end{array}$ & Inheritance \\
\hline 1 & CC hypoplasia & $\operatorname{arr16p11.2(28,708,186-29,088,624)\times 1}$ & 380 & $10(4)$ & Loss & $\begin{array}{l}\text { 16p11.2 distal } \\
\text { deletion syndrome }\end{array}$ & Pathogenic & No & De novo \\
\hline 2 & Short CC & arr9p24.3q13(208,454-68,216,577)x2-3 & 68,008 & $>100(45)$ & $\begin{array}{l}\text { Gain } \\
\text { (mosaicism) }\end{array}$ & $\begin{array}{l}\text { 9p arm duplication } \\
\text { (suspected marker } \\
\text { chromosome) }\end{array}$ & Pathogenic & Yes & De novo \\
\hline 3 & $\begin{array}{l}\text { Partial agenesis of } \\
\text { the CC (M) }\end{array}$ & $\operatorname{arrXp22.2(10,239,680-10,455,210)\times 2}$ & 216 & $1(1)$ & Gain & $\begin{array}{l}\text { MID1 partial gene } \\
\text { duplication (X- } \\
\text { linked Opitz G/BBB } \\
\text { syndrome) }\end{array}$ & VUS & No & Maternal \\
\hline 4 & $\begin{array}{l}\text { Short and thin CC } \\
\text { and ventricular } \\
\text { septal defect }\end{array}$ & arr4q31.3q32.1(153,129,815-161,751,205)×1 & 8,621 & $29(12)$ & Loss & $\begin{array}{l}4 q 31-4 q 32 \\
\text { interstitial deletion }\end{array}$ & Pathogenic & No & De novo \\
\hline 5 & $\begin{array}{l}\text { Agenesis of the CC } \\
\text { and hypospadias }\end{array}$ & $\operatorname{arr} 2 q 22.3(144,800,569-145,403,092) \times 1$ & 602 & $2(1)$ & Loss & $\begin{array}{l}\text { 2q22 interstitial } \\
\text { deletion (ZEB2 } \\
\text { whole gene } \\
\text { deletion: Mowat- } \\
\text { Wilson syndrome) }\end{array}$ & Pathogenic & No & $\begin{array}{l}\text { Not } \\
\text { reported }\end{array}$ \\
\hline \multirow[t]{2}{*}{6} & $\begin{array}{l}\text { CC hypoplasia, } \\
\text { SUA, and clubfoot }\end{array}$ & arr18p11.32q21.2(163,170-48,343,892)X3 & 48,181 & $>100(44)$ & Gain & $\begin{array}{l}\text { 18p11.32q21.2 } \\
\text { duplication (part of } \\
\text { isochromosome } \\
\text { 18) }\end{array}$ & Pathogenic & Yes & De novo \\
\hline & & $\operatorname{arr18q21.2q23(48,344,498-78,015,180)\times 1}$ & 29,671 & $82(23)$ & Loss & $\begin{array}{l}\text { 18q21.2q23 } \\
\text { deletion (part of } \\
\text { isochromosome } \\
\text { 18) }\end{array}$ & Pathogenic & Yes & De novo \\
\hline \multirow[t]{2}{*}{7} & $\begin{array}{l}\text { Blake pouch cyst } \\
\text { (F) }\end{array}$ & arr6p25.3p25.2(156,974-4,042,130)x1 & 3,885 & $21(7)$ & Loss & $\begin{array}{l}6 \mathrm{p} 25.3 \text { terminal } \\
\text { deletion }\end{array}$ & Pathogenic & No & De novo \\
\hline & & $\operatorname{arrXp22.33(168,551-1,782,068)\times 1}$ & 1,614 & $12(2)$ & Loss & $\begin{array}{l}\text { SHOX whole gene } \\
\text { deletion (Leri-Weill } \\
\text { dyschondrostosis) }\end{array}$ & Pathogenic & No & De novo \\
\hline 8 & $\begin{array}{l}\text { Cerebellar } \\
\text { hypoplasia (F) }\end{array}$ & $\operatorname{arrXp11.4(41,121,851-41,899,020)\times 1}$ & 777 & $5(3)$ & Loss & $\begin{array}{l}\text { Xp11.4 interstitial } \\
\text { deletion (CASK } \\
\text { whole gene } \\
\text { deletion: FG } \\
\text { syndrome) }\end{array}$ & Pathogenic & No & $\begin{array}{l}\text { Not } \\
\text { reported }\end{array}$ \\
\hline 9 & $\begin{array}{l}\text { Vermian } \\
\text { hypoplasia and } \\
\text { diaphragmatic } \\
\text { hernia }\end{array}$ & arr12p13.3p11.1(173,786-34,835,641)×3-4 & 34,662 & $>100(64)$ & $\begin{array}{l}\text { Gain } \\
\text { (mosaicism) }\end{array}$ & $\begin{array}{l}\text { Pallister Killian } \\
\text { syndrome }\end{array}$ & Pathogenic & Yes & De novo \\
\hline \multirow[t]{2}{*}{10} & $\begin{array}{l}\text { Cerebellar } \\
\text { hypoplasia, } \\
\text { ventriculomegaly, } \\
\text { thickened nuchal } \\
\text { fold, and } \\
\text { shortening of long } \\
\text { bones }\end{array}$ & arr21q11.2q22.3(15,016,486-48,093,361)×3 & 33,077 & $>100(44)$ & Gain & Down syndrome & Pathogenic & Yes & $\begin{array}{l}\text { Not } \\
\text { reported }\end{array}$ \\
\hline & & $\operatorname{arr} 22 q 11.21(20,312,660-21,461,017) \times 3$ & 1,148 & $15(5)$ & Gain & $\begin{array}{l}\text { Partial proximal } \\
22 q 11 \text { duplication } \\
\text { syndrome (LCR -B } \\
\text { to LCR-D) }\end{array}$ & VUS & No & $\begin{array}{l}\text { Not } \\
\text { reported }\end{array}$ \\
\hline 11 & $\begin{array}{l}\text { PFA (most } \\
\text { probably Dandy- } \\
\text { Walker } \\
\text { malformation), } \\
\text { persistent left } \\
\text { superior vena } \\
\text { cava, and right } \\
\text { heart ventricular } \\
\text { hypertrophy }\end{array}$ & $\operatorname{arr1q21.1q21.2(146,023,922-148,016,122)\times 1}$ & 1,992 & $13(2)$ & Loss & $\begin{array}{l}\text { 1q21 distal } \\
\text { deletion syndrome }\end{array}$ & $\begin{array}{l}\text { Likely } \\
\text { pathogenic }\end{array}$ & No & $\begin{array}{l}\text { Not } \\
\text { reported }\end{array}$ \\
\hline 12 & $\begin{array}{l}\text { Mega cisterna } \\
\text { magna and mild } \\
\text { bilateral } \\
\text { ventriculomegaly }\end{array}$ & $\operatorname{arr} 22 q 11.23(23,650,872-24,963,935) \times 3$ & 1,313 & $22(6)$ & Gain & $\begin{array}{l}\text { Partial 22q11 } \\
\text { duplication } \\
\text { syndrome (LCR -G } \\
\text { to LCR-H) }\end{array}$ & VUS & No & $\begin{array}{l}\text { Not } \\
\text { reported }\end{array}$ \\
\hline 13 & $\begin{array}{l}\text { Partial agenesis of } \\
\text { the CC, cerebellar } \\
\text { hypoplasia, } \\
\text { polymicrogyria, } \\
\text { choanal atresia, } \\
\text { and frontal } \\
\text { bossing (F) }\end{array}$ & $\operatorname{arrXq13.1(67,851,675-68,138,195)\times 1}$ & 287 & $2(1)$ & Loss & $\begin{array}{l}\text { Xq13.1 interstitial } \\
\text { deletion (EFNB1 } \\
\text { whole gene } \\
\text { deletion: } \\
\text { Craniofrontonasal } \\
\text { syndrome) }\end{array}$ & $\begin{array}{l}\text { Likely } \\
\text { pathogenic }\end{array}$ & No & Paternal \\
\hline
\end{tabular}


Table 3 Clinically Significant CMA Findings and Variants of Unknown Significance in Pregnancies With CCA and/or PFA (continued)

\begin{tabular}{|c|c|c|c|c|c|c|c|c|c|}
\hline Case & $\begin{array}{l}\text { Sonographic } \\
\text { anomalies }\end{array}$ & CMA result (ISCN*) array GRCh37/hg19 & $\begin{array}{l}\text { Size } \\
\text { (kb) }\end{array}$ & $\begin{array}{l}\text { Number } \\
\text { of OMIM } \\
\text { genes } \\
\text { (morbid } \\
\text { genes) }\end{array}$ & CNV type & CNV information & Classification & $\begin{array}{l}\text { Karyotype } \\
\text { detectable }\end{array}$ & Inheritance \\
\hline \multirow[t]{2}{*}{14} & $\begin{array}{l}\text { Vermian } \\
\text { hypoplasia/ } \\
\text { agenesis, agenesis } \\
\text { of the CC, lateral } \\
\text { ventriculomegaly, } \\
\text { micrognathia, } \\
\text { intrauterine } \\
\text { growth restriction, } \\
\text { SUA, and absent } \\
\text { or small stomach }\end{array}$ & arr1q43q44(237,251,147-249,224,684)x1 & 11,974 & $37(11)$ & Loss & $\begin{array}{l}1 \mathrm{q} 43 \text { terminal } \\
\text { deletion (probably } \\
\text { part of unbalanced } \\
\text { reciprocal } \\
\text { translocation) }\end{array}$ & Pathogenic & Yes & De novo \\
\hline & & $\operatorname{arr} 16 q 23.3 q 24.3(82,184,504-90,155,062) \times 3$ & 7,971 & $73(31)$ & Gain & $\begin{array}{l}16 q 23 \text { terminal } \\
\text { duplication } \\
\text { (probably part of } \\
\text { unbalanced } \\
\text { reciprocal } \\
\text { translocation) }\end{array}$ & Pathogenic & No & De novo \\
\hline
\end{tabular}

Abbreviations: $C C$ = corpus callosum; CCA = corpus callosum anomalies; $C M A=$ chromosomal microarray analysis; $C N V=$ copy number variant; $F=$ female; ISCN = International System for Human Cytogenetic Nomenclature; LCR = low copy repeats; M = male; OMIM = Online Mendelian Inheritance in Man; PFA = posterior fossa anomalies; SUA = single umbilical artery; VUS = variant of unknown significance.

Cases 1-6 refer to CCA, 7-12 to PFA, and cases 13-14 combine both.

$\mathrm{X}$-linked dominant mental retardation and microcephaly with pontine and cerebellar hypoplasia (MIM \#300749). ${ }^{\mathrm{e}, \mathrm{e} 3}$

In case 13 (a female fetus with partial agenesis of the CC, cerebellar hypoplasia, polymicrogyria, choanal atresia, and frontal bossing), we detected a paternally inherited deletion in Xq13.1, encompassing the EFNB1 gene. Heterozygous mutations in EFNB1 cause craniofrontonasal syndrome (MIM \#304110), which may include partial or complete agenesis of
CC. ${ }^{\mathrm{e}-\mathrm{e} 6}$ This disorder manifests more severely in females than males $^{\mathrm{e} 7, \mathrm{e} 8}$ (potentially explaining the self-reported healthy father), and the CNV was classified as likely pathogenic. The pregnancy was terminated, and therefore we cannot assess the presence of other postnatal characteristics of this disorder.

In other cases, the association of the reported $\mathrm{CNV}$ and the brain anomaly is less well established. In case 1 , a de novo distal 16p11.2 deletion was detected in a fetus with CC

Table 4 Relative Risk of Clinically Significant CMA Results in Pregnancies From the Current Study Compared to Control Groups of Pregnancies With Normal US

\begin{tabular}{|c|c|c|}
\hline Group (Clinically significant CMA results/overall) & $\begin{array}{l}\text { Compared to } 5,541 \text { pregnancies, } \\
\text { with } 1.4 \% \text { detection rate } \text { ra }^{49} \\
\text { (relative risk, } 95 \% \mathrm{CI} \text { ) }\end{array}$ & $\begin{array}{l}\text { Compared to } 2,752 \text { low-risk } \\
\text { pregnancies, with } 0.76 \% \text { detection } \\
\text { rate }^{49} \text { (relative risk, } 95 \% \mathrm{Cl} \text { ) }\end{array}$ \\
\hline \multicolumn{3}{|l|}{ CCA } \\
\hline All (7/102) & $5.16(2.32-11.47)^{a}$ & $9.58(3.97-23.09)^{a}$ \\
\hline Isolated (2/57) & $2.54(0.61-10.62)(p=0.19)$ & $4.72(1.08-20.66)(p=0.023)$ \\
\hline Nonisolated (5/45) & $8.75(3.36-22.77)^{a}$ & $16.25(5.83-45.26)^{a}$ \\
\hline CCA without extra-CNS anomalies (2/78) & $1.84(0.44-7.63)(p=0.31)$ & $3.42(0.78-14.85)(p=0.13)$ \\
\hline CCA with extra-CNS anomalies (5/24) & $18.43(6.71-50.61)^{a}$ & $34.22(11.68-100.24)^{a}$ \\
\hline \multicolumn{3}{|l|}{ PFA } \\
\hline All (7/89) & $5.97(2.67-13.35)^{a}$ & $11.10(4.59-26.85)^{a}$ \\
\hline Isolated (2/50) & $2.91(0.69-12.21)(p=0.16)$ & $5.41(1.23-23.76)^{a}(p=0.012)$ \\
\hline Nonisolated (5/39) & $10.30(3.92-27.03)^{a}$ & $19.12(6.81-53.69)^{a}$ \\
\hline PFA without extra-CNS anomalies (2/60) & $2.41(0.58-10.06)(p=0.21)$ & $4.48(1.02-19.57)(p=0.029)$ \\
\hline PFA with extra-CNS anomalies (5/29) & $14.59(5.42-39.23)^{a}$ & $27.09(9.43-77.79)^{a}$ \\
\hline
\end{tabular}

Abbreviations: $C C A=$ corpus callosum anomalies; $\mathrm{Cl}=$ confidence interval; $\mathrm{CMA}=$ chromosomal microarray analysis; $\mathrm{PFA}=$ posterior fossa anomalies ${ }^{a} p<0.001$. 
hypoplasia. This finding, classified as pathogenic, is mainly associated with neurodevelopmental phenotypes with incomplete penetrance, and according of our knowledge, CCA were not previously reported in affected individuals. ${ }^{\text {e,e } 10} \mathrm{On}$ the other hand, this CNV has been associated (negative doseresponse) with intracranial volume and volume of basal ganglia structures. ${ }^{\text {e11 }}$ A 1q21 distal microdeletion was observed in a fetus with PFA (probably Dandy-Walker malformation), persistent left superior vena cava, and right heart ventricular hypertrophy (case 11). The syndrome caused by the CNV has a wide range of manifestations, including cardiac and brain anomalies, ${ }^{\text {e12 }}$ but PFA has not yet been described as part of it.

In some pregnancies, more than 1 finding was observed. In case 7 , with Blake pouch cyst, we found a distal 6p25.3 deletion of approximately $4 \mathrm{Mb}$. The $6 \mathrm{p}$ terminal deletion syndrome is described in the literature, and PFA (in particular DandyWalker malformation) is one of its features, potentially due to deletion of the FOXC1 gene. ${ }^{\text {e13-e15 }}$ Additional CNV noticed in this female fetus was a deletion in Xp22.33, which harbored the SHOX gene, located in a pseudoautosomal region. Although probably incidental and nonrelated to the US phenotype, we classified this $\mathrm{CNV}$ as pathogenic due to SHOX involvement in a known syndrome with a wide clinical spectrum. ${ }^{\text {e16,e17 }}$

Three CNVs were classified as VUS, 2 of them involving duplication of the 22q11 region: partial proximal 22q11 duplication (low copy repeats (LCR)-B to LCR-D) in case 10 and more distal duplication (LCR-G to LCR-H) in case 12. These CNVs are associated with 2 different syndromes with incomplete penetrance and mainly neurodevelopmental or neuropsychiatric manifestations. ${ }^{\text {e18,e19 }}$ Consistent with previous reports, ${ }^{\text {e20,e21 }}$ and since the relevance of these CNVs (within their specific positions) to the prenatal US anomalies was unclear, they were classified as VUS (in case 10, the phenotype is probably better explained by a diagnosis of Down syndrome).

A male fetus (case 3) with partial agenesis of the CC had a 216 $\mathrm{kb}$ duplication in Xp22.2, including part (exons 4-10) of the MID1 gene, inherited from a self-reported healthy mother. Mutations in MID1 cause X-linked Opitz G/BBB syndrome (MIM \#300000). ${ }^{\text {e22 }}$ At least some of MID1 mutations are related to loss of function mechanisms, ${ }^{\mathrm{e} 3, \mathrm{e} 24}$ but duplications of exons 1 or 2 were reported as pathogenic. ${ }^{\mathrm{e} 5, \mathrm{e} 26}$ However, because the functional role of the duplication is not known, the fetus had no other features of this syndrome (except CCA), and familial segregation was not completed, we regarded this finding as VUS.

\section{Discussion}

We investigated the frequency of CMA with clinically significant results in fetal CCA or PFA, in a nationwide cohort of pregnant women who underwent invasive testing. The overall rate of CMA with clinically significant findings was $6.9 \%$ for pregnancies with CCA and 7.9\% for pregnancies with PFA. Although the rate was higher in nonisolated than in isolated cases, it was not statistically significant. However, the detection rate among pregnancies that had extra-CNS sonographic anomalies (with or without other CNS involvement) was significantly elevated compared to all other cases (isolated or with additional CNS anomalies only). The risk of CMA detection rate in pregnancies with CCA or PFA (all, nonisolated and cases with extra-CNS anomalies) was significantly higher than in pregnancies with normal US from a control cohort and subgroup of low-risk pregnancies $(p<$ 0.001 ). Results were not significant for isolated pregnancies, as well as for cases without extra-CNS anomalies, compared to the whole cohort. Only $40 \%$ and $6.67 \%$ of the clinically significant genomic alterations were karyotype and NIPS detectable, respectively. Taken together, our findings support the benefit of CMA in pregnancies with CCA or PFA, and it is probably most informative in cases with extra-CNS anomalies.

The contribution of chromosomal aberrations and CNVs to CCA has been studied mainly in postnatal settings. For example, a meta-analysis of 27 studies found chromosomal anomalies in $4.81 \%$ and $7.45 \%$ of complete and partial agenesis of the CC, respectively. ${ }^{14}$ Among 149 patients with CCA and intellectual disability, $13 \%$ had at least $1 \mathrm{CNV}$ that likely contributed to the phenotype. ${ }^{\text {e27 }}$ In the prenatal setting, however, data are more limited, and CMA yield is variable. Microarray (performed pre- or postnatally) detected a causal chromosomal anomaly in 2 of 18 pregnancies (11.1\%) with isolated complete agenesis of the CC on US examination. ${ }^{24}$ In 16 fetuses with isolated agenesis of the CC, She et al. ${ }^{25}$ found 2 cases with pathogenic CNV (12.5\%). In additional study of 69 pregnancies with agenesis of the CC and normal karyotype (when performed), the diagnostic rate of microarray analysis was $5.8 \%$ (4.4\% in isolated and $8.3 \%$ in cases with additional structural anomalies in other systems). ${ }^{26}$ On the other hand, no pathogenic $\mathrm{CNV}$ s were found in 32 fetuses with CCA in 8 years observational study from a tertiary care university hospital. $^{28}$ Finally, a study of 65 fetuses with abnormalities of the $\mathrm{CC}$ identified pathogenic $\mathrm{CNV}$ in 3 cases (4.5\%), whereas exome sequencing found a pathogenic single-nucleotide variant in $12(18 \%))^{27}$

The role of CMA in fetuses with PFA was also investigated previously with variable results, but the detection rate was generally higher than in our study. ${ }^{26,28-32}$ Among 77 pregnancies with PFA that underwent CMA, Zou et al. ${ }^{30}$ found chromosomal aberrations (including pathogenic CNVs and VUSs) in $31.2 \%$ of all cases, and in $18.5 \%$ of fetuses with normal karyotypes. In another study of 144 pregnancies with PFA tested by microarrays, the detection rate of clinically significant genomic alterations was $14.6 \%$ (6.8\% in isolated and $22.9 \%$ in cases with additional structural anomalies in other systems). ${ }^{26}$ Lei et al. ${ }^{29}$ found no chromosomal aneuploidies or pathogenic CNVs in 30 fetuses with isolated PFA or in 13 PFA cases accompanied by other CNS abnormalities. However, the rate of these findings in fetuses with PFA and extra-CNS structural 
abnormalities was $54.8 \%$ (17 out 31 ). Santirocco et al. ${ }^{28}$ reported that among 31 fetuses with PFA, prevalence of pathogenic CNVs was $12.9 \%$ (11.8\% in isolation and $15.4 \%$ in fetuses with complex abnormalities), a higher rate than for other types CNS anomalies that were investigated. Last, in fetuses with cerebellar vermis defects, CMA provided diagnosis in 10/ 43 cases $(23.3 \%)$, significantly higher in fetuses with multiple malformations compared to isolated, whereas exome sequencing yielded diagnostic genetic variants in $8 / 19(42.1 \%){ }^{31}$

In general, involvement of additional CNS or extra-CNS anomalies probably increases the likelihood to detect genomic disorder in the affected fetus, compare to isolated CCA or PFA. The lack of significant differences in part of our analyses may stem from the limited number of cases. Our study encompassed a relatively large number of CMA tests from pregnancies with a rather rare condition of fetal CCA or PFA, collected from a nationwide database. However, it is likely that a larger sample size with increased power would have facilitated reaching more definitive conclusions, including narrower $\mathrm{CIs}$ and more accurate estimates of relative risk.

One should keep in mind that this study sample does not include all pregnancies with CCA or PFA in Israel during the investigated time period. Part of the pregnant woman do not undergo the recommended sonographic surveys, whereas others avoid invasive testing. Moreover, the rising use of NIPS at earlier stages of pregnancy and the recommendation to have first and second trimester Down syndrome screening, facilitate early detection of pregnancies at risk for chromosomal aneuploidies. These factors decrease the rate of abnormal pregnancies, which could be later sonographically diagnosed with CCA or PFA. It is also plausible that in some pregnancies with suspected diagnosis of common trisomies, early prenatal diagnosis by rapid tests (like quantitative fluorescent PCR) eliminated the need to further perform CMA. Last, when multiple anomalies are observed in the fetus in early sonographic evaluation, parents may decide to terminate the pregnancy without having an invasive prenatal testing.

The specific types of anomalies included in the CCA and PFA groups are heterogeneous, with a wide spectrum of severity. For example, the CCA group includes fetuses with complete agenesis of the CC, as well as fetuses with only short but complete CC or other unspecified CC anomaly. The definition of the short $\mathrm{CC}$ is also variable and considered by some authors as a CC length below the fifth percentile ${ }^{\mathrm{e} 28}$. In some cases, the distinction between hypoplastic, short, and CC within the normal range is challenging, especially when fetal MRI is not performed. The heterogeneity of CCA and PFA types in our analysis may explain the difference in CMA detection rate compared to the studies discussed above.

Notably, CMA testing did not lead to molecular diagnosis in more than $90 \%$ of pregnancies, and the etiology remained unexplained. Further genetic evaluation, including fetal whole-exome sequencing, could assist in resolving an additional part of the undiagnosed cases. ${ }^{27,31}$
Several additional limitations of the current study should be acknowledged. The clinical data are based on referral indications for invasive testing and CMA, and were collected retrospectively. Sonographic evaluations were taken by multiple gynecologists across Israel, using different equipment, which may lead to inter-rater variability. Follow-up data of US or fetal brain MRI from later stages of pregnancy were unavailable. All these may have influenced the accuracy of anomaly classification and categorization to isolated and nonisolated cases. For example, in some conditions, CCA and ventriculomegaly (mainly of a mild degree) may represent a single structural anomaly rather than 2 separate findings. We considered cases with this combination as nonisolated CCA, due to a lack of further follow-up imaging information and for the sake of simplicity, but in some cases, this classification is probably not accurate.

A further drawback is lack of data regarding the outcomes of the pregnancies, including termination or postnatal developmental outcomes and imaging follow-up (when pregnancies were continued). Other limitation is primarily technical, due to the fact that CMA tests were conducted and interpreted by several different laboratories rather than a single one. To overcome this, we revised the classification of all reported CMA findings based on current knowledge.

In conclusion, our findings demonstrate that in pregnancies with sonographic diagnosis of CCA or PFA, CMA testing may be beneficial for the genetic workup and contribute to the prenatal counseling. Future studies in larger samples with both prenatal and postnatal assessment are required to better define the CMA detection rate in isolated and nonisolated CCA and PFA pregnancies, as well as in specific anomaly types.

\section{Study Funding}

The invasive tests, as well as CMA, were funded as part of the public health services in Israel.

\section{Disclosure}

The authors report no disclosures relevant to the manuscript. Go to Neurology.org/NG for full disclosures.

\section{Publication History}

Received by Neurology: Genetics April 11, 2020. Accepted in final form February 17, 2021.

\section{Appendix Authors}

\begin{tabular}{lll}
\hline Name & Location & Contribution \\
\hline $\begin{array}{l}\text { Lior } \\
\text { Mreenbaum, PhD }\end{array}$ & $\begin{array}{l}\text { Sheba Medical } \\
\text { Center, Tel } \\
\text { Hashomer, Israel }\end{array}$ & $\begin{array}{l}\text { Study design, data acquisition } \\
\text { and research, and manuscript } \\
\text { writing }\end{array}$ \\
\hline Idit Maya, MD & $\begin{array}{l}\text { Rabin Medical } \\
\text { Center, Petach } \\
\text { Tikva, Israel }\end{array}$ & $\begin{array}{l}\text { Study design, interpretations of } \\
\text { data, and revision of the } \\
\text { manuscript for intellectual } \\
\text { content }\end{array}$ \\
\hline
\end{tabular}


Appendix (continued)

\begin{tabular}{|c|c|c|}
\hline Name & Location & Contribution \\
\hline $\begin{array}{l}\text { Lena Sagi- } \\
\text { Dain, MD }\end{array}$ & $\begin{array}{l}\text { Carmel Medical } \\
\text { Center, Haifa, Israel }\end{array}$ & $\begin{array}{l}\text { Study design, interpretation of data, } \\
\text { and revision of the manuscript for } \\
\text { intellectual content }\end{array}$ \\
\hline $\begin{array}{l}\text { Rivka } \\
\text { Sukenik- } \\
\text { Halevy, MD }\end{array}$ & $\begin{array}{l}\text { Rabin Medical } \\
\text { Center, Petach } \\
\text { Tikva, Israel }\end{array}$ & $\begin{array}{l}\text { Revision of the manuscript for } \\
\text { intellectual content }\end{array}$ \\
\hline $\begin{array}{l}\text { Michal } \\
\text { Berkenstadt, } \\
\text { PhD }\end{array}$ & $\begin{array}{l}\text { Sheba Medical } \\
\text { Center, Tel } \\
\text { Hashomer, Israel }\end{array}$ & $\begin{array}{l}\text { Revision of the manuscript for } \\
\text { intellectual content }\end{array}$ \\
\hline $\begin{array}{l}\text { Hagith } \\
\text { Yonath, MD }\end{array}$ & $\begin{array}{l}\text { Sheba Medical } \\
\text { Center, Tel } \\
\text { Hashomer, Israel }\end{array}$ & $\begin{array}{l}\text { Revision of the manuscript for } \\
\text { intellectual content }\end{array}$ \\
\hline $\begin{array}{l}\text { Shlomit } \\
\text { Rienstein, } \\
\text { PhD }\end{array}$ & $\begin{array}{l}\text { Sheba Medical } \\
\text { Center, Tel } \\
\text { Hashomer, Israel }\end{array}$ & $\begin{array}{l}\text { Revision of the manuscript for } \\
\text { intellectual content }\end{array}$ \\
\hline $\begin{array}{l}\text { Adel Shalata, } \\
\text { MD, PhD }\end{array}$ & $\begin{array}{l}\text { Bnai Zion Medical } \\
\text { Center, Haifa, Israel }\end{array}$ & $\begin{array}{l}\text { Revision of the manuscript for } \\
\text { intellectual content }\end{array}$ \\
\hline $\begin{array}{l}\text { Eldad } \\
\text { Katorza, MD, } \\
\text { MSc, MBA }\end{array}$ & $\begin{array}{l}\text { Sheba Medical } \\
\text { Center, Tel } \\
\text { Hashomer, Israel }\end{array}$ & $\begin{array}{l}\text { Study design, interpretation of data, } \\
\text { and revision of the manuscript for } \\
\text { intellectual content }\end{array}$ \\
\hline $\begin{array}{l}\text { Amihood } \\
\text { Singer, MD }\end{array}$ & $\begin{array}{l}\text { Ministry of Health, } \\
\text { Jerusalem, Israel }\end{array}$ & $\begin{array}{l}\text { Study design and supervision, data } \\
\text { acquisition and research, and } \\
\text { manuscript writing }\end{array}$ \\
\hline
\end{tabular}

\section{References}

1. Hillman SC, McMullan DJ, Hall G, et al. Use of prenatal chromosomal microarray: prospective cohort study and systematic review and meta-analysis. Ultrasound Obstet Gynecol 2013;41:610-620.

2. Novelli A, Grati FR, Ballarati L, et al. Microarray application in prenatal diagnosis: a position statement from the cytogenetics working group of the Italian Society of Human Genetics (SIGU), November 2011. Ultrasound Obstet Gynecol 2012;39:384-388.

3. Wapner RJ, Martin CL, Levy B, et al. Chromosomal microarray versus karyotyping for prenatal diagnosis. N Engl J Med 2012;367:2175-2184.

4. Committee on Genetics and the Society for Maternal-Fetal Medicine. Committee Opinion No. 682: microarrays and next-generation sequencing technology: the use of advanced genetic diagnostic tools in Obstetrics and gynecology. Obstet Gynecol 2016;128:e262-e268.

5. American College of Obstetricians and Gynecologists' Committee on Practice Bulletins-Obstetrics. Committee on Genetics, and Society for Maternal-Fetal Medicine. Practice bulletin no. 162: prenatal diagnostic testing for genetic disorders. Obstet Gynecol 2016;127:e108-e122.

6. Cotes C, Bonfante E, Lazor J, et al. Congenital basis of posterior fossa anomalies. Neuroradiol J 2015;28:238-253.

7. D'Antonio F, Khalil A, Garel C, et al. Systematic review and meta-analysis of isolated posterior fossa malformations on prenatal ultrasound imaging (part 1): nomenclature, diagnostic accuracy and associated anomalies. Ultrasound Obstet Gynecol 2016;47:690-697.

8. Edwards TJ, Sherr EH, Barkovich AJ, Richards LJ. Clinical, genetic and imaging findings identify new causes for corpus callosum development syndromes. Brain 2014;137:1579-1613.

9. Palmer EE, Mowat D. Agenesis of the corpus callosum: a clinical approach to diagnosis. Am J Med Genet C Semin Med Genet 2014;166C:184-197.

10. Al-Hashim AH, Blaser S, Raybaud C, MacGregor D. Corpus callosum abnormalities: neuroradiological and clinical correlations. Dev Med Child Neurol 2016;58:475-484.

11. Wahl M, Ziemann U. The human motor corpus callosum. Rev Neurosci 2008;19:451-466

12. Hanna RM, Marsh SE, Swistun D, et al. Distinguishing 3 classes of corpus callosal abnormalities in consanguineous families. Neurology 2011;76:373-382.

13. Sotiriadis A, Makrydimas G. Neurodevelopment after prenatal diagnosis of isolated agenesis of the corpus callosum: an integrative review. Am J Obstet Gynecol 2012;206:337.e1-337.e5.

14. D'Antonio F, Pagani G, Familiari A, et al. Outcomes associated with isolated agenesis of the corpus callosum: a meta-analysis. Pediatrics 2016;138:e20160445.

15. Glass HC, Shaw GM, Ma C, Sherr EH. Agenesis of the corpus callosum in California 1983-2003: a population-based study. Am J Med Genet A 2008;146A:2495-2500.

16. Jeret JS, Serur D, Wisniewski K, Fisch C. Frequency of agenesis of the corpus callosum in the developmentally disabled population as determined by computerized tomography. Pediatr Neurosci 1985;12:101-103.

17. Chapman T, Mahalingam S, Ishak GE, Nixon JN, Siebert J, Dighe MK. Diagnostic imaging of posterior fossa anomalies in the fetus and neonate: part 1, normal anatomy and classification of anomalies. Clin Imaging 2015;39:1-8.

18. Chapman T, Mahalingam S, Ishak GE, Nixon JN, Siebert J, Dighe MK. Diagnostic imaging of posterior fossa anomalies in the fetus and neonate: part 2, Posterior fossa disorders. Clin Imaging 2015;39:167-175.
19. Robinson AJ, Ederies MA. Diagnostic imaging of posterior fossa anomalies in the fetus. Semin Fetal Neonatal Med 2016;21:312-320.

20. Ghali R, Reidy K, Fink AM, Palma-Dias R. Perinatal and short-term neonatal outcomes of posterior fossa anomalies. Fetal Diagn Ther 2014;35:108-117.

21. D'Antonio F, Khalil A, Garel C, et al. Systematic review and meta-analysis of isolated posterior fossa malformations on prenatal imaging (part 2): neurodevelopmental outcome. Ultrasound Obstet Gynecol 2016;48:28-37.

22. Howley MM, Keppler-Noreuil KM, Cunniff CM, Browne ML; National Birth Defects Prevention Study. Descriptive epidemiology of cerebellar hypoplasia in the national birth defects prevention study. Birth Defects Res 2018;110:1419-1432.

23. Santoro M, Coi A, Barišić I, et al. Epidemiology of dandy-walker malformation in Europe: a EUROCAT population-based Registry study. Neuroepidemiology 2019;53:169-179.

24. de Wit MC, Boekhorst F, Mancini GM, et al. Advanced genomic testing may aid in counseling of isolated agenesis of the corpus callosum on prenatal ultrasound. Prenat Diagn 2017;37:1191-1197.

25. She Q, Fu F, Guo X, Tan W, Liao C. Genetic testing in fetuses with isolated agenesis of the corpus callosum. J Matern Fetal Neonatal Med 2019;1-201.

26. Shaffer LG, Rosenfeld JA, Dabell MP, et al. Detection rates of clinically significant genomic alterations by microarray analysis for specific anomalies detected by ultrasound. Prenat Diagn 2012;32:986-995.

27. Heide S, Spentchian M, Valence S, et al. Prenatal exome sequencing in 65 fetuses with abnormality of the corpus callosum: contribution to further diagnostic delineation. Genet Med 2020;22:1887-1891.

28. Santirocco M, Plaja A, Rodó C, et al. Chromosomal microarray analysis in fetuses with central nervous system anomalies: an 8-year long observational study from a tertiary care university hospital. Prenat Diagn 2021;41:123-135.

29. Lei T, Feng J-L, Xie Y-J, Xie H-N, Zheng J, Lin M-F. Chromosomal aneuploidies and copy number variations in posterior fossa abnormalities diagnosed by prenatal ultrasonography. Prenat Diagn 2017;37:1160-1168.

30. Zou Z, Huang L, Lin S, et al. Prenatal diagnosis of posterior fossa anomalies: additional value of chromosomal microarray analysis in fetuses with cerebellar hypoplasia. Prenat Diagn 2018;38:91-98.

31. Li L, Fu F, Li R, et al. Genetic tests aid in counseling of fetuses with cerebellar vermis defects. Prenat Diagn 2020;40:1228-1238.

32. Sun L, Wu Q, Jiang S-W, et al. Prenatal diagnosis of central nervous system Anomalies by high-Resolution chromosomal microarray analysis. Biomed Res Int 2015;2015:426379.

33. Maya I, Singer A, Yonath $\mathrm{H}$, et al. What have we learned from 691 prenatal chromosomal microarrays for ventricular septal defects? Acta Obstet Gynecol Scand 2020;99:757-764.

34. Sagi-Dain L, Singer A, Josefsberg S, et al. Microarray analysis has no additional value in fetal aberrant right subclavian artery: description of 268 pregnancies and systematic literature review. Ultrasound Obstet Gynecol 2019;53:810-815.

35. Singer A, Maya I, Banne E, et al. Prenatal clubfoot increases the risk for clinically significant chromosomal microarray results - analysis of 269 singleton pregnancies. Early Hum Dev 2020;145:105047.

36. Sagi-Dain L, Singer A, Hadid Y, et al. Non-visualization of fetal gallbladder in microarray era-a retrospective cohort study and review of the literature. J Matern Fetal Neonatal Med 2019;32:2643-2648.

37. Sagi-Dain L, Maya I, Falik-Zaccai T, et al. Isolated fetal horseshoe kidney does not seem to increase the risk for abnormal chromosomal microarray results. Eur J Obstet Gynecol Reprod Biol 2018;222:80-83.

38. Singer A, Maya I, Sukenik-Halevy R, et al. Microarray findings in pregnancies with oligohydramnios - a retrospective cohort study and literature review. J Perinat Med 2019;48:53-58

39. Singer A, Maya I, Koifman A, et al. Microarray analysis in pregnancies with isolated echogenic bowel. Early Hum Dev 2018;119:25-28.

40. Sagi-Dain L, Singer A, Frumkin A, et al. Chromosomal microarray findings in preg nancies with an isolated pelvic kidney. J Perinat Med 2018;47:30-34.

41. Sagi-Dain L, Maya I, Reches A, et al. Chromosomal microarray analysis results from pregnancies with various ultrasonographic anomalies. Obstet Gynecol 2018;132:1368-1375.

42. Tzadikevitch Geffen K, Singer A, Maya I, et al. Chromosomal microarray should be performed for cases of fetal short long bones detected prenatally. Arch Gynecol Obstet 2020;40:1228-1238.

43. Pasternak Y, Singer A, Maya I, et al. The yield of chromosomal microarray testing for cases of abnormal fetal head circumference. J Perinat Med 2020;48:553-558.

44. Maya I, Singer A, Baris HN, et al. Prenatal microarray analysis in right aortic arch-a retrospective cohort study and review of the literature. J Perinatol 2018;38:468-473.

45. Singer A, Maya I, Frumkin A, et al. Is fetal isolated double renal collecting system an indication for chromosomal microarray? J Matern Fetal Neonatal Med 2021;34:696-700.

46. Sagi-Dain L, Maya I, Peleg A, et al. Microarray analysis in pregnancies with isolated unilateral kidney agenesis. Pediatr Res 2018;83:825-828.

47. Hosseinzadeh K, Luo J, Borhani A, Hill L. Non-visualisation of cavum septi pellucidi: implication in prenatal diagnosis? Insights Imaging 2013;4:357-367.

48. Riggs ER, Andersen EF, Cherry AM, et al. Technical standards for the interpretation and reporting of constitutional copy-number variants: a joint consensus recommendation of the American College of Medical Genetics and Genomics (ACMG) and the Clinical Genome Resource (ClinGen). Genet Med 2020;22:245-257.

49. Sagi-Dain L, Cohen Vig L, Kahana S, et al. Chromosomal microarray vs. NIPS analysis of 5541 low-risk pregnancies. Genet Med 2019;21:2462-2467.

50. Adam MP, Conta J, Bean LJ. Mowat-Wilson syndrome. In Adam MP, Ardinger $\mathrm{HH}$ Pagon RA, Wallace SE, Bean LJ, Stephens K, Amemiya A, editors. GeneReviews ${ }^{\circledR}$. Seattle: University of Washington; 1993.

(Additional references e1-e28 are available at: lww.com/NXG/A408.) 


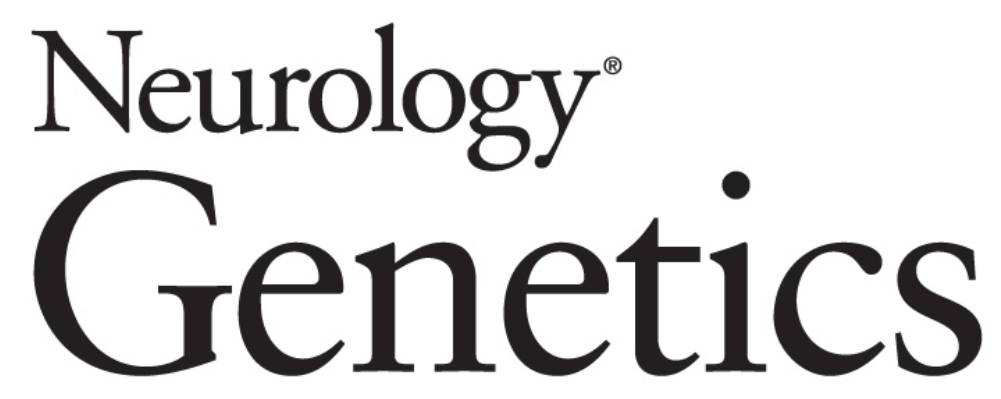

\section{Chromosomal Microarray Analysis in Pregnancies With Corpus Callosum or Posterior Fossa Anomalies}

Lior Greenbaum, Idit Maya, Lena Sagi-Dain, et al. Neurol Genet 2021;7;

DOI 10.1212/NXG.0000000000000585

\section{This information is current as of May 28, 2021}

\section{Updated Information \&} Services

References

Permissions \& Licensing

Reprints including high resolution figures, can be found at: http://ng.neurology.org/content/7/3/e585.full.html

This article cites 48 articles, 0 of which you can access for free at: http://ng.neurology.org/content/7/3/e585.full.html\#\#ref-list-1

Information about reproducing this article in parts (figures,tables) or in its entirety can be found online at:

http://ng.neurology.org/misc/about.xhtml\#permissions

Information about ordering reprints can be found online: http://ng.neurology.org/misc/addir.xhtml\#reprintsus

Neurol Genet is an official journal of the American Academy of Neurology. Published since April 2015, it is an open-access, online-only, continuous publication journal. Copyright Copyright @ 2021 The Author(s). Published by Wolters Kluwer Health, Inc. on behalf of the American Academy of Neurology.. All rights reserved. Online ISSN: 2376-7839.

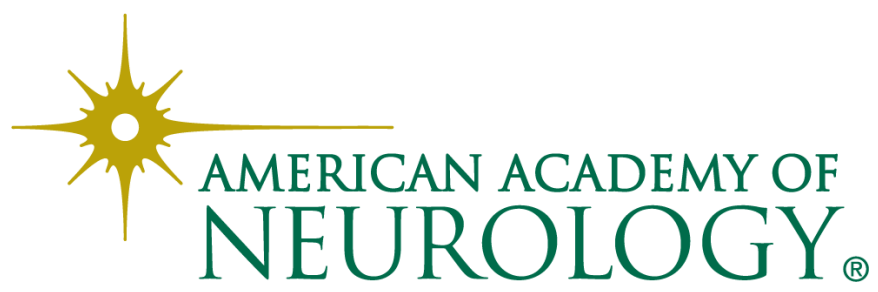

